\title{
A novel methodology for assessing the environmental sustainability of ionic liquids used for $\mathrm{CO}_{2}$ capture $\uparrow$
}

\author{
Rosa M. Cuéllar-Franca, ${ }^{\text {*a }}$ Pelayo García-Gutiérrez, ${ }^{a}$ \\ S. F. Rebecca Taylor, ${ }^{\text {ab }}$ Christopher Hardacre ${ }^{\text {ab }}$ and Adisa Azapagic ${ }^{a}$
}

Received 15th March 2016, Accepted 20th April 2016

DOI: $10.1039 / c 6 f d 00054 a$

Ionic liquids (ILs) have been proposed as suitable sorbents for $\mathrm{CO}_{2}$ capture because of their high $\mathrm{CO}_{2}$ absorption capacity, thermal stability, negligible vapour pressure and physicochemical tunability. However, the environmental implications of ILs are currently largely unknown because of a lack of data. The issue is further complicated by their complex chemical structures and numerous precursors for which environmental data are scarce or non-existent. In an attempt to address this issue, this paper presents a new methodology for estimating life cycle environmental impacts of novel ILs, with the aim of aiding synthesis and selection of more sustainable $\mathrm{CO}_{2}$ sorbents. The methodology consists of four main steps: (1) selection of an appropriate IL and synthesis route; (2) construction of a life cycle tree; (3) life cycle assessment; and (4) recommendations for improvements. The application of the methodology is illustrated using trihexyltetradecylphosphonium 1,2,4-triazolide ( $\left[\mathrm{P}_{66614}\right]$ [124Triz]), a promising IL for $\mathrm{CO}_{2}$ capture currently under development. Following the above steps, the paper demonstrates how the data obtained from laboratory synthesis of the IL can be scaled up to industrial production to estimate life cycle impacts and identify environmental hotspots. In this particular case, the main hotspots are the precursors used in the synthesis of the IL. Comparison of impacts with monoethanolamine (MEA), currently the most widely-used $\mathrm{CO}_{2}$ sorbent, suggests that $\left[\mathrm{P}_{66614}\right][124$ Triz] has much higher impacts than MEA, including global warming potential. However, human toxicity potential is significantly higher for MEA. Therefore, the proposed methodology can be used to optimise the design of ILs and to guide selection of more sustainable $\mathrm{CO}_{2}$ sorbents. Although the focus is on ILs, the methodology is generic and can be applied to other chemicals under development.

\section{Introduction}

Reducing greenhouse gas (GHG) emissions has become a major global challenge, with many countries seeking to implement appropriate solutions to mitigate

${ }^{a}$ School of Chemical Engineering and Analytical Science, The University of Manchester, The Mill, Sackville Street, Manchester M13 9PL, UK. E-mail: rosa.cuellarfranca@manchester.ac.uk

${ }^{b}$ School of Chemistry and Chemical Engineering, Queen's University, Belfast, Northern Ireland BT9 5AG, UK $\dagger$ Electronic supplementary information (ESI) available. See DOI: 10.1039/c6fd00054a 
climate change. Carbon capture and storage (CCS) and carbon capture and utilisation (CCU) are considered as promising options that could help towards addressing this challenge. ${ }^{1-3}$ However, they are both constrained by the efficiency of $\mathrm{CO}_{2}$ capture, which can significantly influence their economic and environmental sustainability. Thus, further development of $\mathrm{CO}_{2}$ capture processes aiming to reduce costs and environmental impacts is important for successful deployment of CCS and CCU at a large scale.

Currently, the most mature and widely-used method for $\mathrm{CO}_{2}$ capture is postcombustion absorption in monoethanolamine (MEA). ${ }^{4-6}$ The advantages of MEA are its high $\mathrm{CO}_{2}$ absorption capacity and relatively low cost. However, MEA is toxic, corrosive at elevated temperatures and expensive to regenerate because of the large enthalpy of $\mathrm{CO}_{2}$ absorption $\left(-85 \mathrm{~kJ} \mathrm{~mol}^{-1} \text { at } 40{ }^{\circ} \mathrm{C}\right)^{7}$ and heat losses through vaporization..$^{6,89}$ Therefore, development of more sustainable sorbents is one of the main challenges for CCS and CCU.

In recent years, various alternatives to MEA have been suggested, including KS-1 solvent, Econamine $\mathrm{FG}^{+\mathrm{SM}}$, amidoxime, metal-organic frameworks, microporous organic polymers, zeolitic imidazolate frameworks and membranes, and ionic liquids (ILs). ${ }^{10}$ The latter are considered an attractive alternative to aminebased solvents because of their high $\mathrm{CO}_{2}$ solubility and related absorption capacity, extremely low vapour pressure and low corrosivity. ${ }^{\mathbf{8 , 9}, 11}$ Furthermore, the vast number of possible combinations of cations and anions allow the solvent to be custom-made for specific applications. ${ }^{10} \mathrm{~A}$ recent study which tested tetraalkylphosphonium superbase ILs reported that, at room temperature and atmospheric pressure, trihexyltetradecylphosphonium 1,2,4-triazolide $\left(\left[\mathrm{P}_{66614}\right]\right.$ [124Triz]) $\left(\mathrm{C}_{34} \mathrm{H}_{71} \mathrm{PN}_{3}\right)$ had equimolar $\mathrm{CO}_{2}$ uptake under dry conditions and slightly below that under wet conditions. ${ }^{7}$ Thus, these results suggest that $\left[\mathrm{P}_{66614}\right]$ [124Triz] is a promising sorbent for $\mathrm{CO}_{2}$ capture.

However, before novel ILs such as $\left[\mathrm{P}_{66614}\right][124$ Triz $]$ can be used as alternatives to conventional sorbents, it is necessary to understand their environmental implications, to avoid solving one environmental problem - climate change - at the expense of other impacts. It is also important that the environmental evaluation be carried out on a life cycle basis, to ensure that the impacts are not shifted from one life cycle stage to another, a problem known as 'leakage' of environmental impacts. This is not a trivial task, as life cycle impacts of novel ILs are as yet unknown because they are still being developed, and data for their manufacture and use at an industrial scale are limited. This is further complicated by their complex synthesis routes involving numerous precursors for which life cycle data are scarce or non-existent.

In an attempt to address this issue, this paper presents a novel methodology for estimating life cycle environmental impacts of ILs under development, with the aim of identifying hotspots and aiding synthesis and selection of more sustainable sorbents. Although the focus here is on ILs, the methodology is generic enough to be applicable to other chemicals. The example of $\left[\mathrm{P}_{66614}\right][124 \mathrm{Triz}]$ is used to illustrate the application of the methodology by estimating its life cycle environmental impacts in comparison to MEA. The next section describes the proposed methodology, followed by its application in Section 3. The conclusions and recommendations for future work are given in Section 4. 


\section{Methodology}

The proposed methodology for estimating the life cycle environmental impacts of novel ILs, outlined in Fig. 1, comprises four main steps:

(1) selection of an IL and its preparation method;

(2) construction of a life cycle tree for the selected IL;

(3) life cycle assessment (LCA); and

(4) recommendations for improvements.

These steps are described in more detail in the following sections.

\subsection{Step 1: selection of ionic liquid and synthesis route}

As shown in Fig. 1, the first step involves selecting an IL and identifying the synthesis route(s) available for its production. In the case of commercially available ILs, it is possible that more than one route will exist. In that case, the most prevalent commercial process should be selected to ensure representative results. For ILs under development, i.e. synthesised only at a laboratory scale, the preparation method known or used at the time of the assessment should be considered.

\subsection{Step 2: construction of a life cycle tree}

ILs usually have a complex structure involving numerous precursors for which life cycle data are scarce or not available. To address this issue, a life cycle tree of the IL under study is constructed in the second step (Fig. 1), tracing back to the basic precursors for which life cycle data are available (e.g. hydrogen, ammonia, benzene, methanol, etc.).

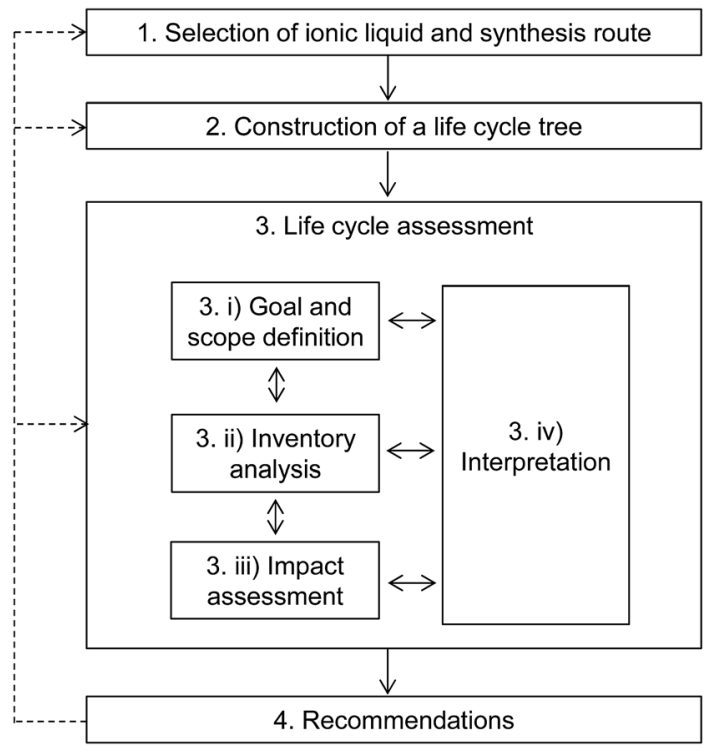

Fig. 1 Proposed methodology for assessing life cycle environmental sustainability of ionic liquids. 
Similarly to ILs, it is likely that more than one synthesis route will be available for the precursors, so the most prevalent commercial route should be selected whenever possible. This information can be sourced from scientific journals, patents, chemical handbooks, technology encyclopedias and industry.

Following the completion of the life cycle tree, an LCA of the selected IL can be carried out as outlined below.

\subsection{Step 3: life cycle assessment}

As indicated in Fig. 1, LCA involves four phases: ${ }^{12,13}$

(i) goal and scope of the study: definition of the goal of the study, system boundaries, functional unit (unit of analysis) and assumptions;

(ii) inventory analysis: collection of data on materials and energy used in the system and emissions to air, water and soil;

(iii) environmental impact assessment: estimation of environmental impacts based on the inventory data; and

(iv) interpretation: analysis of the results and comparison of impacts with alternative sorbents to identify hotspots and opportunities for improvements.

For LCA of ILs, the most challenging phase will be the inventory analysis, because of a lack of life cycle inventory data for most novel ILs and their precursors. Furthermore, the data that are available for IL synthesis will be at the laboratory scale, so scaling up to a possible industrial production will be necessary to reflect the actual manufacturing conditions as closely as possible. Different methods can be used for filling data gaps, including stoichiometric, thermodynamics, empirical scale-up and other relevant relationships. The robustness of the results should be tested through sensitivity and uncertainty analyses.

\subsection{Step 4: recommendations for improvement}

In the fourth and final step of the proposed methodology, recommendations for improvements are made based on the findings of the LCA study. For example, these could include a change of the synthesis route, substitution of raw materials, improvements in the energy and atom efficiency or selection of a different ionic liquid. As shown in Fig. 1, this process is iterative, with the recommendations fed back to the preceding steps, as needed.

The next section illustrates how the proposed methodology can be applied, using the IL $\left[\mathrm{P}_{66614}\right][124$ Triz $]$ as an example.

\section{Application of the methodology: the case of [P66614][124Triz]}

\subsection{Step 1: selection of ionic liquid and synthesis route}

As mentioned earlier, $\left[\mathrm{P}_{66614}\right][124 \mathrm{Triz}]$ represents a promising sorbent for $\mathrm{CO}_{2}$ capture based on its high (equimolar) $\mathrm{CO}_{2}$ uptake at room temperature and atmospheric pressure, under both dry and wet conditions. ${ }^{7}$ In comparison to amino-acid based ILs, which can also achieve equimolar absorption, superbase ILs are not subject to large viscosity increases after $\mathrm{CO}_{2}$ absorption and are thus more suitable for practical applications. ${ }^{7}$ Phosphonium-based ILs are also much cheaper than other classes of ILs. Moreover, $\left[\mathrm{P}_{66614}\right][124 \mathrm{Triz}]$ has recently been 


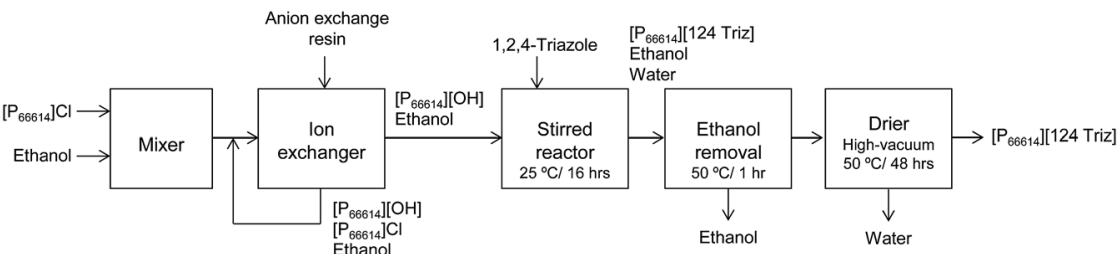

Fig. 2 Synthesis of [P66614][124Triz] (adapted from Taylor et al.7).

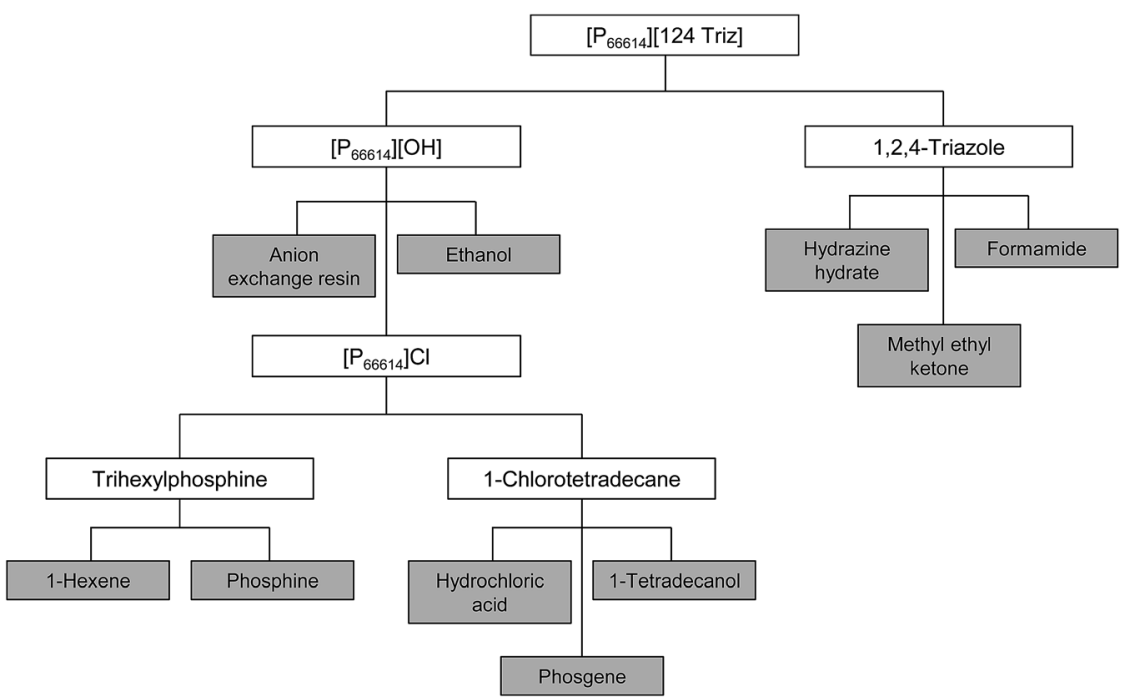

Fig. 3 The life cycle tree for the production of $\left[\mathrm{P}_{66614}\right][124$ Triz] (the shaded boxes indicate the compounds for which data are available in LCA databases. Data for the compounds shown in clear boxes are not available).

used successfully for $\mathrm{CO}_{2}$ conversion to formate via electrochemical reduction, ${ }^{\mathbf{1 4}}$ which suggests that it could also be used for carbon utilisation, in addition to capture.

$\left[\mathrm{P}_{66614}\right][124$ Triz $]$ was synthesised by reacting trihexyl(tetradecyl)phosphonium hydroxide $\left(\left[\mathrm{P}_{66614}\right][\mathrm{OH}]\right)$ and 1,2,4-triazole in ethanol (Fig. 2). The reactants were mixed in a $1: 1 \mathrm{~mol}$ ratio and stirred for 16 hours at room temperature to produce a solution containing $\left[\mathrm{P}_{66614}\right][124 \mathrm{Triz}]$, ethanol and water. Ethanol was removed in a rotary evaporator at $50{ }^{\circ} \mathrm{C}$ for one hour. Finally, the IL solution was dried in a rotary evaporator at $50{ }^{\circ} \mathrm{C}$ and under high-vacuum conditions for 48 hours. The overall production yield was in excess of $90 \%$. Further details on the production process are provided in the next section.

\subsection{Step 2: construction of the life cycle tree}

Neither of the two compounds used in the synthesis of $\left[\mathrm{P}_{66614}\right][124 \mathrm{Triz}]\left(\left[\mathrm{P}_{66614}\right]\right.$ $[\mathrm{OH}]$ and 1,2,4-triazole) are available in LCA databases, so they had to be traced back to their basic precursors through the construction of a life cycle tree, as shown in Fig. 3. These precursors were identified based on the prevalent 
Table 1 Precursors for commercial production of $\left[\mathrm{P}_{66614}\right][124$ Triz]

\begin{tabular}{|c|c|c|}
\hline Compound & Precursors & Source \\
\hline$\left[\mathrm{P}_{66614}\right][\mathrm{OH}]$ & {$\left[\mathrm{P}_{66614}\right] \mathrm{Cl}$} & Taylor et al. ${ }^{7}$ \\
\hline$\left[\mathrm{P}_{66614}\right] \mathrm{Cl}$ & $\begin{array}{l}\text { Trihexylphosphine } \\
\text { 1-Chlorotetradecane }\end{array}$ & Bradaric et al. ${ }^{15}$ \\
\hline Trihexylphosphine & $\begin{array}{l}\text { Phosphine } \\
\text { 1-Hexene }\end{array}$ & Rauhut et al. ${ }^{16}$ \\
\hline 1-Chlorotetradecane & $\begin{array}{l}\text { Hydrochloric acid } \\
\text { 1-Tetradecanol } \\
\text { Phosgene }\end{array}$ & Demail et al. ${ }^{17}$ \\
\hline 1,2,4-Triazole & $\begin{array}{l}\text { Formamide } \\
\text { Hydrazine hydrate }\end{array}$ & Petree et $a l . .^{18}$ \\
\hline
\end{tabular}

Table 2 Chemical reactions involved in the production of $\left[\mathrm{P}_{66614}\right][124$ Triz] and its precursors

\begin{tabular}{|c|c|c|}
\hline \multicolumn{2}{|l|}{ Compound } & Chemical reactions $^{a}$ \\
\hline \multicolumn{2}{|l|}{$\left[\mathrm{P}_{66614}\right][124$ Triz $]$} & $\begin{array}{l}{\left[\mathrm{P}\left(\mathrm{CH}_{2}\left(\mathrm{CH}_{2}\right)_{4} \mathrm{CH}_{3}\right)_{3}\left(\mathrm{CH}_{2}\left(\mathrm{CH}_{2}\right)_{12} \mathrm{CH}_{3}\right)\right]} \\
{[\mathrm{OH}]+\mathrm{HNNCHNCH} \rightarrow} \\
{\left[\mathbf{P}\left(\mathbf{C H}_{2}\left(\mathbf{C H}_{2}\right)_{\mathbf{4}} \mathbf{C H}_{3}\right)_{3}\left(\mathbf{C H}_{2}\left(\mathbf{C H}_{2}\right)_{12} \mathbf{C H}_{3}\right)\right][\mathbf{N N C H N C H}]} \\
+\mathrm{H}_{2} \mathrm{O}\end{array}$ \\
\hline$\left[\mathrm{P}_{66614}\right] \mathrm{OH}$ & & $\begin{array}{l}{\left[\mathrm{P}\left(\mathrm{CH}_{2}\left(\mathrm{CH}_{2}\right)_{4} \mathrm{CH}_{3}\right)_{3}\left(\mathrm{CH}_{2}\left(\mathrm{CH}_{2}\right)_{12} \mathrm{CH}_{3}\right)\right][\mathrm{Cl}]} \\
+\overline{\mathrm{R}} \mathrm{OH} \rightarrow\left[\mathbf{P}\left(\mathbf{C H}_{2}\left(\mathbf{C H}_{2}\right)_{4} \mathbf{C H}_{3}\right)_{3}\left(\mathbf{C H}_{2}\left(\mathbf{C H}_{2}\right)_{12} \mathbf{C H}_{3}\right)\right] \\
{[\mathbf{O H}]+\overline{\mathrm{R}} \mathrm{Cl}}\end{array}$ \\
\hline$\left[\mathrm{P}_{66614}\right] \mathrm{Cl}$ & & $\begin{array}{l}\mathrm{P}\left(\mathrm{CH}_{2}\left(\mathrm{CH}_{2}\right)_{4} \mathrm{CH}_{3}\right)_{3}+\mathrm{CH}_{3}\left(\mathrm{CH}_{2}\right)_{13} \mathrm{Cl} \rightarrow \\
{\left[\mathbf{P}\left(\mathrm{CH}_{2}\left(\mathbf{C H}_{2}\right)_{4} \mathbf{C H}_{3}\right)_{3}\left(\mathbf{C H}_{2}\left(\mathbf{C H}_{2}\right)_{12} \mathbf{C H}_{3}\right)\right][\mathrm{Cl}]+\mathrm{HCl}}\end{array}$ \\
\hline Trihexylphosphine & & $\begin{array}{l}\mathrm{PH}_{3}+\mathrm{CH}_{2} \mathrm{CH}\left(\mathrm{CH}_{2}\right)_{3} \mathrm{CH}_{3} \rightarrow \mathrm{P}\left(\mathrm{CH}_{2}\left(\mathrm{CH}_{2}\right)_{4} \mathrm{CH}_{3}\right)_{3} \\
+\mathrm{PH}_{3}+\mathrm{CH}_{2} \mathrm{CH}\left(\mathrm{CH}_{2}\right)_{3} \mathrm{CH}_{3}\end{array}$ \\
\hline 1-Chlorotetradecane & $\begin{array}{l}\text { Reaction (i) } \\
\text { Reaction (ii) }\end{array}$ & $\begin{array}{l}\mathrm{CH}_{3}\left(\mathrm{CH}_{2}\right)_{13} \mathrm{OH}+\mathrm{HCl} \rightarrow \mathbf{C H}_{3}\left(\mathbf{C H}_{2}\right)_{13} \mathbf{C l} \\
+\mathrm{CH}_{3}\left(\mathrm{CH}_{2}\right)_{13} \mathrm{OH}+\mathrm{CH}_{3}\left(\mathrm{CH}_{2}\right)_{13} \mathrm{O}\left(\mathrm{CH}_{2}\right)_{13} \mathrm{CH}_{3}+\mathrm{H}_{2} \mathrm{O} \\
\mathrm{CH}_{3}\left(\mathrm{CH}_{2}\right)_{13} \mathrm{OH}+\mathrm{COCl}_{2} \rightarrow \mathrm{CH}_{3}\left(\mathrm{CH}_{2}\right)_{12} \mathrm{Cl} \\
+\mathrm{CH}_{3}\left(\mathrm{CH}_{2}\right)_{13} \mathrm{O}\left(\mathrm{CH}_{2}\right)_{13} \mathrm{CH}_{3} \\
+\mathrm{CH}_{3}\left(\mathrm{CH}_{2}\right)_{13} \mathrm{OCOO}\left(\mathrm{CH}_{2}\right)_{13} \mathrm{CH}_{3}+\mathrm{HCl}+\mathrm{COCl}_{2}\end{array}$ \\
\hline 1,2,4-Triazole & & $\begin{array}{l}\mathrm{CH}_{3} \mathrm{NO}+\mathrm{N}_{2} \mathrm{H}_{4} \cdot \mathrm{H}_{2} \mathrm{O} \rightarrow \text { HNNCHNCH } \\
+\mathrm{CH}_{3} \mathrm{NO}+\mathrm{N}_{2} \mathrm{H}_{4}+\mathrm{NH}_{3}+\mathrm{HCOOH}+\mathrm{H}_{2} \mathrm{O} \\
+\left[\mathrm{NH}_{4}\right]\left[\mathrm{HCO}_{2}\right]\end{array}$ \\
\hline
\end{tabular}

${ }^{a}$ The bold font in the column "Chemical reactions" indicates the main compounds produced, corresponding to the respective compounds in the column "Compound".

commercial production routes found in the literature (see Table 1). A brief description of the synthesis of each precursor is given below and summarised in Table 2; for further details, see Section 1 in ESI. $\dagger$

3.2.1. Trihexyl(tetradecyl)phosphonium hydroxide ([ $\left.\left.\mathbf{P}_{66614}\right][\mathrm{OH}]\right)$. As shown in Fig. 2, this IL can be synthesised from trihexyl(tetradecyl)phosphonium chloride $\left(\left[\mathrm{P}_{66614}\right] \mathrm{Cl}\right)$ using an anion exchange resin such as Amberlite IRN-78 (OH-form) and ethanol at ambient temperature and atmospheric pressure. ${ }^{7}$ As indicated in Fig. 3, the latter two are available in LCA databases but $\left[\mathrm{P}_{66614}\right] \mathrm{Cl}$ is not, so its precursors need to be identified to enable estimation of its life cycle impacts.

3.2.2. Trihexyl(tetradecyl)phosphonium chloride $\left(\left[\mathbf{P}_{66614}\right] \mathrm{Cl}\right)$. Cytec, a leading commercial manufacturer of ILs, synthesises this IL by reacting 
trihexylphosphine and 1-chlorotetradecane at $140{ }^{\circ} \mathrm{C}$ and atmospheric pressure, followed by a separation step; the overall yield is $93.9 \% .^{15}$ Neither of these chemicals is available in LCA databases; hence, it is necessary to identify their precursors.

3.2.3. Trihexylphosphine. Tertiary organophosphines, such as trihexylphosphine, are commonly synthesised from the free-radical addition of phosphine to unsaturated compounds such as 1-hexene in the presence of a free radical promoter. ${ }^{16}$ Under specific temperature and pressure conditions (e.g. $70{ }^{\circ} \mathrm{C}$ and 3.4 bar), this reaction can produce tertiary organophosphines as the predominant product with a yield of $>80 \%$ with respect to the unsaturated compound. ${ }^{16}$ As indicated in Fig. 3, life cycle inventory data for both phosphine and hexane are available in LCA databases, which will allow estimation of the LCA impacts of trihexylphosphine in the next step of the methodology.

3.2.4. 1-Chlorotetradecane. The second precursor for $\left[\mathrm{P}_{66614}\right] \mathrm{Cl}$ can be synthesised through a nucleophilic substitution reaction between an alcohol and a halogen acid. ${ }^{17}$ This is a two-step process, starting with a reaction between 1-tetradecanol and hydrochloric acid and followed by the addition of phosgene, with separation steps between the reactions. The first step takes place at $140{ }^{\circ} \mathrm{C}$ and 4 bar and the second at $120{ }^{\circ} \mathrm{C}$ and atmospheric pressure. The two reactions can achieve conversions of $60-95 \%$ on a mole basis. As shown in Fig. 3, life cycle inventory data for 1-tetradecanol, hydrochloric acid and phosgene are available in LCA databases, allowing estimation of the LCA impacts of 1-chlorotetradecane. Together with the LCA estimates for trihexylphosphine, it is now possible to determine the LCA impacts of $\left[\mathrm{P}_{66614}\right] \mathrm{Cl}$ and ultimately, the impacts of $\left[\mathrm{P}_{66614}\right][\mathrm{OH}]$.

3.2.5. 1,2,4-Triazole. This precursor for $\left[\mathrm{P}_{66614}\right][124 \mathrm{Triz}]$ can be synthesised from hydrazine hydrate and formamide in a single-step reaction, followed by multiple purification steps using organic solvents, such as methyl ethyl ketone. ${ }^{18}$ The reaction takes place at $170{ }^{\circ} \mathrm{C}$ and atmospheric pressure with yields of 84-90\%. Life cycle inventory data are available in LCA databases for all the precursors.

With all the precursors traced back to the point where all the life cycle inventory data are available, LCA of the target IL $\left(\left[\mathrm{P}_{66614}\right][124 \mathrm{Triz}]\right)$ can now be performed in the next step.

\subsection{Step 3: Life cycle assessment}

As indicated in Fig. 1, the LCA methodology follows the guidelines in the ISO 14040/44 LCA standards. ${ }^{12,13}$ The LCA modelling has been carried out in GaBi V6.4 (ref. 19) and the following impacts have been estimated applying the CML 2001 impact assessment method: ${ }^{20}$ global warming potential (GWP), abiotic depletion potentials for elements and fossil resources (ADP elements and ADP fossil), acidification potential (AP), eutrophication potential (EP), human toxicity potential (HTP), ozone layer depletion potential (ODP), photochemical oxidants creation potential (POCP), fresh water and marine aquatic ecotoxicity potentials (FAETP and MAETP) and terrestrial ecotoxicity potential (TETP).

3.3.1. Goal and scope definition. The goal of the study is to estimate the life cycle environmental impacts of the target IL with the aim of identifying the hotspots and improvement opportunities at an early stage of its development. The functional unit is defined as the 'production of $1 \mathrm{~kg}$ of $\left[\mathrm{P}_{66614}\right][124 \mathrm{Triz}]$ ' and the 


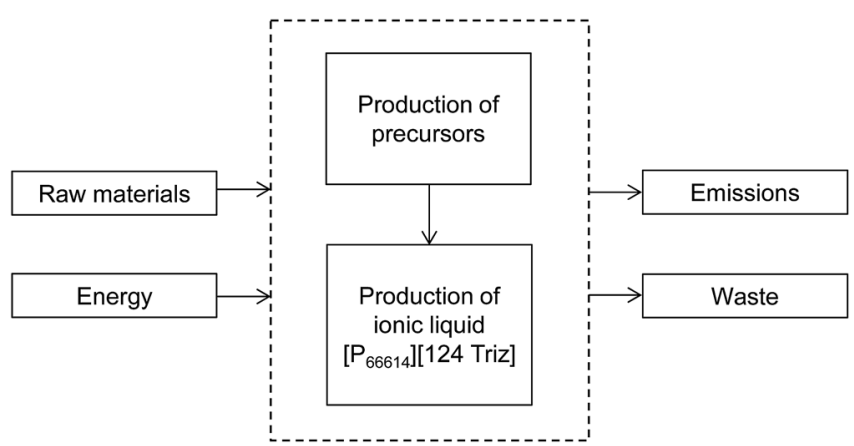

Fig. 4 The system boundary for the production of $\left[\mathrm{P}_{66614}\right][124$ Triz].

system boundaries are from 'cradle to gate' (Fig. 4), including the production of the target IL and all its precursors. In accordance with the goal of the study, the impacts from the use and end-of-life of the IL are excluded from the system boundary.

3.3.2. Inventory analysis. In this step of the methodology, material and energy requirements for the production of $\left[\mathrm{P}_{66614}\right][124 \mathrm{Triz}]$ and its precursors are estimated, as described below.

3.3.2.1 Estimation of material requirements. The raw materials required for the production of each precursor have been estimated using the stoichiometric relationships for the chemical reactions shown in Table 2. The estimations take into account the yields or conversions reported in the literature for each chemical reaction (see Section 3.2 for details). These estimates are given in Table 3. For example, the reaction for the production of $\left[\mathrm{P}_{66614}\right][124 \mathrm{Triz}]$ shown in Table 2 has been balanced for the production of $1 \mathrm{~kg}$ of the IL as follows:

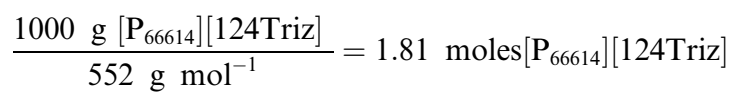

Thus:

$$
\underset{\left[\mathrm{P}_{66614}\right][\mathrm{OH}]}{1.81 \mathrm{C}_{32} \mathrm{H}_{68} \mathrm{OHP}}+\underset{1,2,4 \text {-triazole }}{1.81 \mathrm{C}_{2} \mathrm{H}_{3} \mathrm{~N}_{3}} \rightarrow \stackrel{1.81 \mathrm{C}_{34} \mathrm{H}_{71} \mathrm{PN}_{3}}{\left[\mathrm{P}_{66614}\right][124 \text { Triz }]}
$$

The mass of the reactants is then equal to (see Table S1 in ESI $\uparrow$ for the molecular weights):

$$
\begin{aligned}
& 1.81 \text { moles }\left[\mathrm{P}_{66614}\right][\mathrm{OH}] \times 500 \mathrm{~g} \mathrm{~mol}^{-1}=905 \mathrm{~g}\left[\mathrm{P}_{66614}\right][\mathrm{OH}]
\end{aligned}
$$

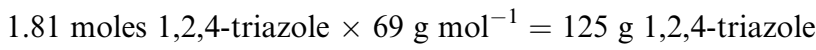

Therefore, $905 \mathrm{~g}$ of $\left[\mathrm{P}_{66614}\right][\mathrm{OH}]$ and $125 \mathrm{~g}$ of 1,2,4-triazole are required to produce $1 \mathrm{~kg}$ of $\left[\mathrm{P}_{66614}\right][124 \mathrm{Triz}]$, also generating $30 \mathrm{~g}$ waste $\left(\mathrm{OH}^{-}\right.$from the anion exchange resin); see Table 3. The calculations for the rest of the raw materials can be found in Section 1 in ESI. $\dagger$ 


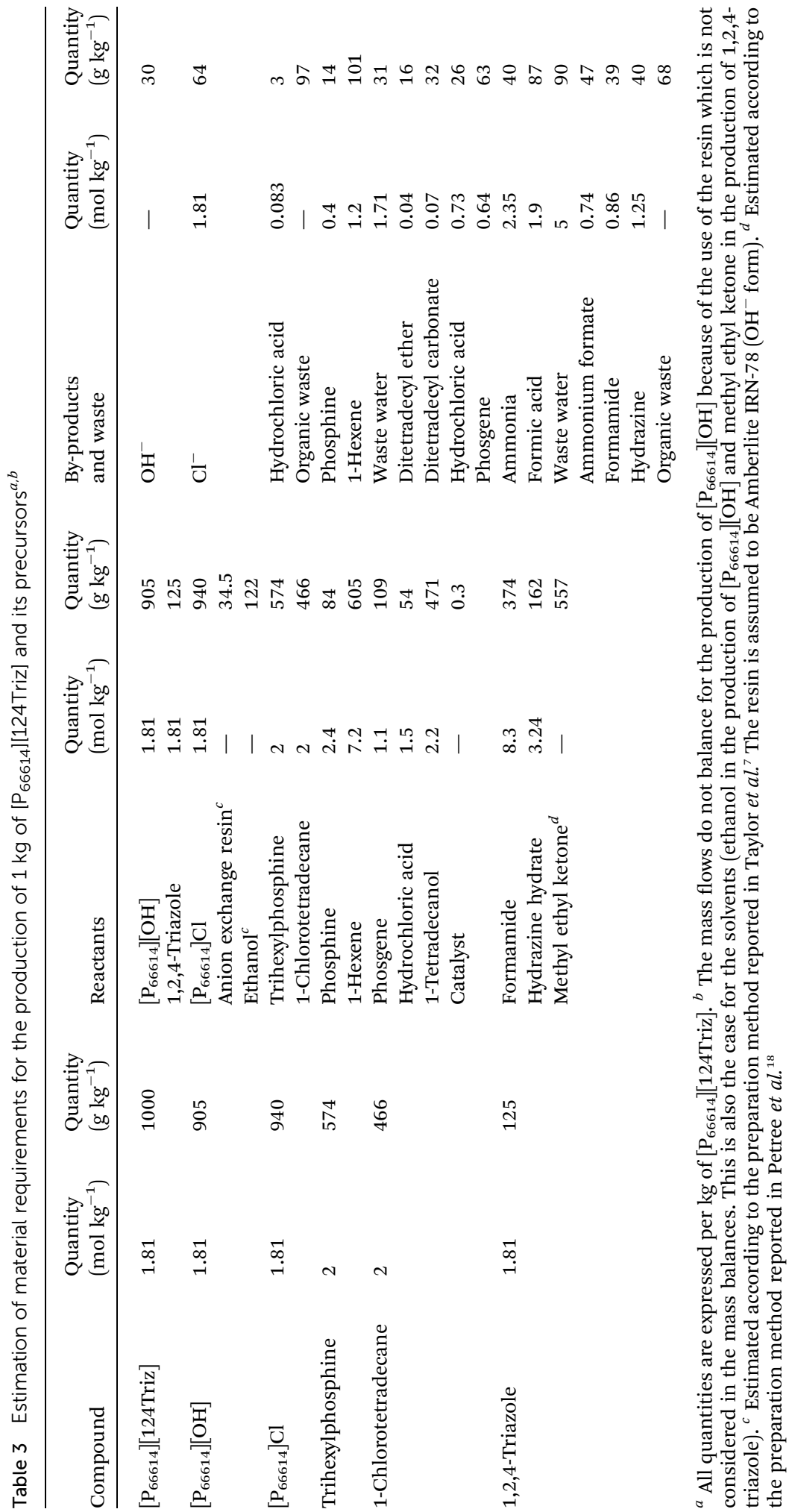


Table 4 Estimation of energy requirements of reactors for the production of $1 \mathrm{~kg}$ of $\left[\mathrm{P}_{66614}\right]\left[124\right.$ Triz] and its precursors ${ }^{a}$

\begin{tabular}{|c|c|c|c|}
\hline Compound & $\begin{array}{l}\text { Theoretical energy } \\
\text { consumption }^{b} \\
\left(\mathrm{MJ} \mathrm{kg}^{-1}\right)\end{array}$ & $\begin{array}{l}\text { Scaled-up energy } \\
\text { consumption }^{c} \\
\left(\mathrm{MJ} \mathrm{kg}{ }^{-1}\right)\end{array}$ & Assumptions \\
\hline$\left[\mathrm{P}_{66614}\right][124$ Triz $]$ & 0.36 & 1.16 & Electricity for cooling \\
\hline$\left[\mathrm{P}_{66614}\right] \mathrm{Cl}$ & 1.71 & 7.21 & Natural gas for heating \\
\hline Trihexylphosphine & 0.31 & 1.30 & Natural gas for heating \\
\hline $\begin{array}{l}\text { 1-Chlorotetradecane } \\
\left(1^{\text {st }} \text { reactor }\right)\end{array}$ & 0.44 & 1.43 & Electricity for cooling \\
\hline $\begin{array}{l}\text { 1-Chlorotetradecane } \\
\left(2^{\text {nd }} \text { reactor }\right)\end{array}$ & 0.042 & 0.175 & Natural gas for heating \\
\hline $\begin{array}{l}1,2,4-\text { Triazole } \\
\left(1^{\text {st }} \text { reactor }\right)\end{array}$ & 1.57 & 6.59 & Natural gas for heating \\
\hline $\begin{array}{l}1,2,4-\text { Triazole } \\
\left(2^{\text {nd }} \text { reactor }\right)\end{array}$ & 0.03 & 0.12 & Natural gas for heating \\
\hline $\begin{array}{l}\text { Total heat } \\
\text { (natural gas) }\end{array}$ & & 15.40 & \\
\hline Total electricity & & 2.59 & \\
\hline \multicolumn{4}{|c|}{$\begin{array}{l}{ }^{a} \text { All energy values expressed per } \mathrm{kg} \text { of }\left[\mathrm{P}_{66614}\right][124 \mathrm{Triz}] .{ }^{b} \text { Estimated using the heat of } \\
\text { formation of reactants and products. Negative values represent an exothermic reaction } \\
\text { and it has been assumed that the reactor is cooled using electricity. }{ }^{c} \text { Estimated using the } \\
\text { theoretical energy values and the empirical factors in Mehrkesh and Karunanithi: }{ }^{22} \\
\text { a factor of } 4.2 \text { has been applied for the heat assuming the use of natural gas and a factor } \\
\text { of } 3.2 \text { for electricity for cooling. }\end{array}$} \\
\hline
\end{tabular}

3.3.2.2 Estimation of energy requirements. As manufacturing data at the industrial scale are not available, a series of assumptions had to be made to estimate energy requirements. First, the theoretical energy consumption for the production of $\left[\mathrm{P}_{66614}\right][124 \mathrm{Triz}]$ and the precursors has been estimated using the heat of formation of reactants and products based on the methods in Felder and Rousseau $^{21}$ and described in Section 2 in ESI. $\dagger$ Secondly, only the energy requirements of reactors (heating and cooling) have been considered as it is not known what other unit operations may be needed in a future commercial production process and what their configuration and capacity might be. Therefore, energy consumption for separation, pumping and other operations is excluded from the estimation; however, the effect of this assumption is tested in the sensitivity and uncertainty analyses later in the paper. Finally, the theoretical energy consumption of reactors has been scaled-up to industrial scale using empirical factors that take into account energy losses. ${ }^{22}$ Thus, the estimated theoretical heat requirements for endothermic reactions have been multiplied by a factor of 4.2, assuming the heat is supplied by natural gas. Similarly, the theoretical amount of heat generated by exothermic reactions has been converted to actual cooling electricity requirements using a factor of 3.2. The results are summarised in Table 4; for further details, see Section 2 in ESI. $\dagger$

3.3.2.3 Life cycle modelling. The material and energy data estimated in the previous two steps and given in Tables 3 and 4 have then been used as the inputs into the LCA model to estimate the impacts of $\left[\mathrm{P}_{66614}\right][124 \mathrm{Triz}]$ production from 'cradle to gate'. The background life cycle inventory data for the materials and energy have largely been sourced from the Ecoinvent database. ${ }^{23}$ The exceptions 
are 1-hexene, 1-tetradecanol, formamide and hydrazine hydrate, for which inventory data are not available and alternative chemicals have been assumed instead. For 1-hexene and 1-tetradecanol, LCA data for n-olefins and fatty alcohols have been used, respectively. This is a reasonable approximation because 1-hexene is an olefin or alkene compound ${ }^{24}$ and 1-tetradecanol is a type of fatty alcohol. ${ }^{25}$ Formamide data have been approximated with the data for formic acid because the former is derived from the latter; ${ }^{26}$ however, this means that the impacts from the conversion of formic acid to formamide are not considered. Finally, data for generic inorganic chemicals have been used to represent hydrazine hydrate as more specific data are not available.

All the raw materials are assumed to be transported to the respective production plants over a distance of $100 \mathrm{~km}$. For energy, it has been assumed that the heat is supplied to the reactors by steam generated from UK natural gas and that electricity is sourced from the UK electricity mix. The waste streams shown in Table 3 are assumed to be treated as industrial wastewater. The system has also been credited for producing the by-products (see Table 3) and so avoiding the impacts which would have otherwise been generated if these products were produced in dedicated commercial plants. The avoided impacts have been estimated by subtracting the LCA impacts of the by-products produced in dedicated facilities (sourced from Ecoinvent) from the total impacts of producing $\left[\mathrm{P}_{66614}\right]$ [124Triz].

3.3.3. Impact assessment. The LCA impacts of $\left[\mathrm{P}_{66614}\right][124 \mathrm{Triz}]$, estimated using the inventory data detailed in the previous section, are presented in Fig. 5. For example, GWP is estimated at $6.3 \mathrm{~kg} \mathrm{CO} 2$ eq. per $\mathrm{kg}\left[\mathrm{P}_{66614}\right][124 \mathrm{Triz}]$, after the

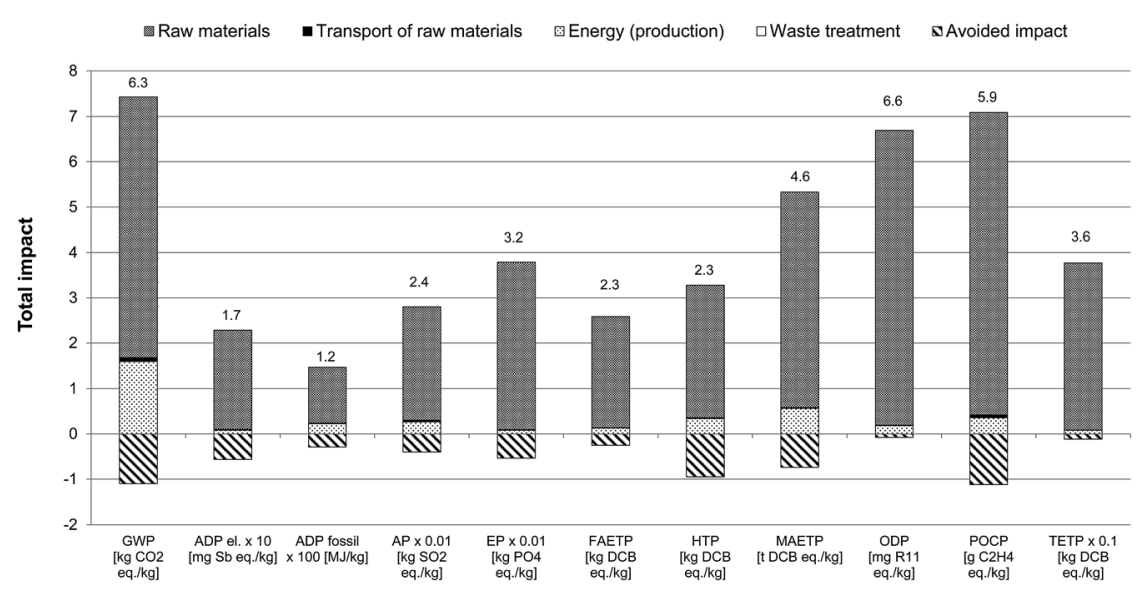

Fig. 5 Environmental impacts of [ $\left.\mathrm{P}_{66614}\right][124 T$ Triz] from cradle to gate (all impacts expressed per kg of $\left[\mathrm{P}_{66614}\right]$ [124Triz]. The values shown on top of each bar represent the total impact after the credits for by-products have been taken into account. The values for some impacts have been scaled to fit on the scale. The original values can be obtained by multiplying the value shown on the $y$-axis by the scaling factor given on the $x$-axis. Impact categories: GWP: global warming potential; ADP elements: abiotic depletion potential of elements; ADP fossil: abiotic depletion potential of fossil resources; AP: acidification potential; EP: eutrophication potential; FAETP: fresh water aquatic ecotoxicity potential; HTP: human toxicity potential; MAETP: marine aquatic ecotoxicity potential; ODP: ozone depletion potential; POCP: photochemical oxidants creation potential; TETP: terrestrial ecotoxicity potential. DCB: dichlorobenzene). 


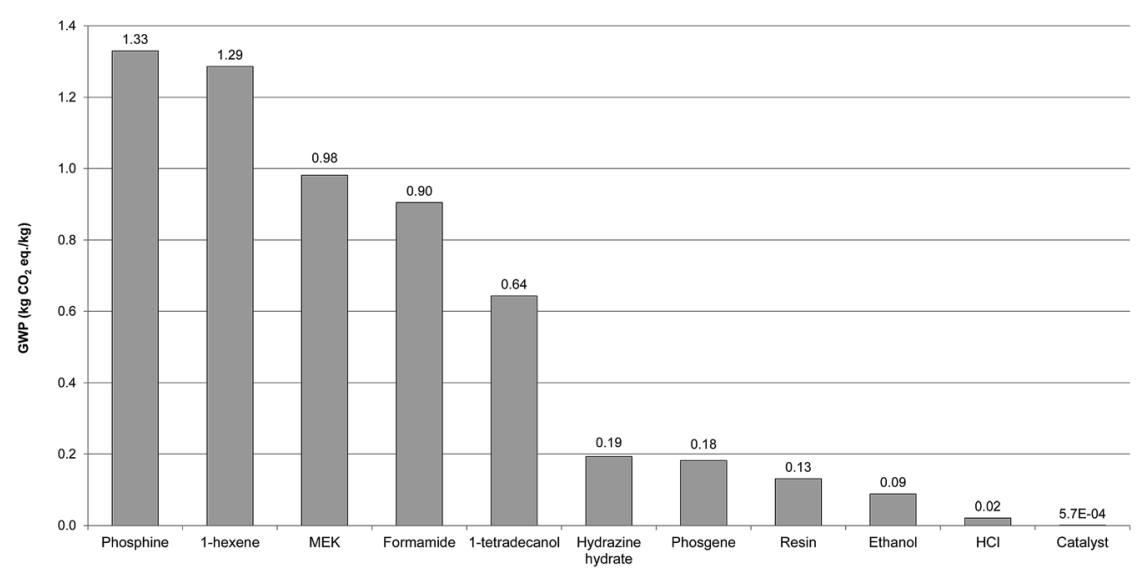

Fig. 6 Contribution of different raw materials to the GWP of [P66614][124Triz] (GWP expressed per kg of [ $\left.\mathrm{P}_{66614}\right][124 \mathrm{Triz}]$. MEK: methyl ethyl ketone; resin: anion exchange).

avoided impact from the by-products $(-1.1 \mathrm{~kg} \mathrm{CO}$ eq. per $\mathrm{kg})$ has been taken into account. Thus, the by-products save $15 \%$ of GHG emissions from the production of $\left[\mathrm{P}_{66614}\right][124 \mathrm{Triz}]$. Similarly to GWP, the credits for the by-products lead to a reduction in all other impacts, most significantly for HTP $(28 \%)$, ADP elements (25\%), ADP fossil (20\%) and POCP (16\%). The main contributors to the impacts and the opportunities for improvements are discussed in the next section.

\subsubsection{Interpretation of results}

3.3.4.1 Identification of hotspots and opportunities for improvements. As indicated in Fig. 5, the raw materials used in the production of the precursors are the main environmental hotspot. In the case of GWP, they contribute $77 \%$ to the total impact, particularly phosphine, 1-hexene, methyl ethyl ketone, formamide and 1-tetradecanol (Fig. 6). The former two, used in the synthesis of trihexylphosphine, the precursor for $\left[\mathrm{P}_{66614}\right] \mathrm{Cl}$, contribute around $23 \%$ each to the GWP of the raw materials. These, together with the other precursors used for $\left[\mathrm{P}_{66614}\right] \mathrm{Cl}$ production, contribute $47 \%$ to the total GWP.

Although only $84 \mathrm{~g}$ of phosphine is required for the production of $1 \mathrm{~kg}$ of $\left[\mathrm{P}_{66614}\right][124 \mathrm{Triz}]$ (see Table 3), its GWP is eight times higher than the average GWP of inorganic chemicals (15.8 $\mathrm{kg} \mathrm{CO}$ eq. per kg phosphine vs. $1.86 \mathrm{~kg} \mathrm{CO}_{2}$ eq. per $\mathrm{kg}$ inorganic chemical). This is due to the energy-intensive production of white elemental phosphorus which is used to produce phosphine. ${ }^{27}$

By comparison, 1-hexene has a relatively low GWP (2 kg CO 2 eq. per $\mathrm{kg}$ ) but, since $605 \mathrm{~g}$ is needed to produce $1 \mathrm{~kg}$ of [ $\left.\mathrm{P}_{66614}\right][124 \mathrm{Triz}]$, its overall contribution to the GWP is relatively high. Similarly, methyl ethyl ketone, formamide and 1-tetradecanol have a relatively low $\operatorname{GWP}\left(1.76,2\right.$ and $1.4 \mathrm{~kg} \mathrm{CO}_{2}$ eq. per $\mathrm{kg}$, respectively), but are used in larger quantities (see Table 3), thus contributing 14$17 \%$ to the GWP of the raw materials.

Energy consumption is the second largest contributor to the GWP of $\left[\mathrm{P}_{66614}\right]$ [124Triz], causing $22 \%$ of this impact, mainly because of the highly endothermic reactions in the synthesis of $\left[\mathrm{P}_{66614}\right] \mathrm{Cl}$ and 1,2,4-triazole, as well as the cooling requirements in the synthesis of 1-chlorotetradecane (see Section 2 in ESI $\dagger$ ).

The raw materials are also the main contributors to the other impact categories (Fig. 5). However, their average contribution is higher than for GWP (93\%, 


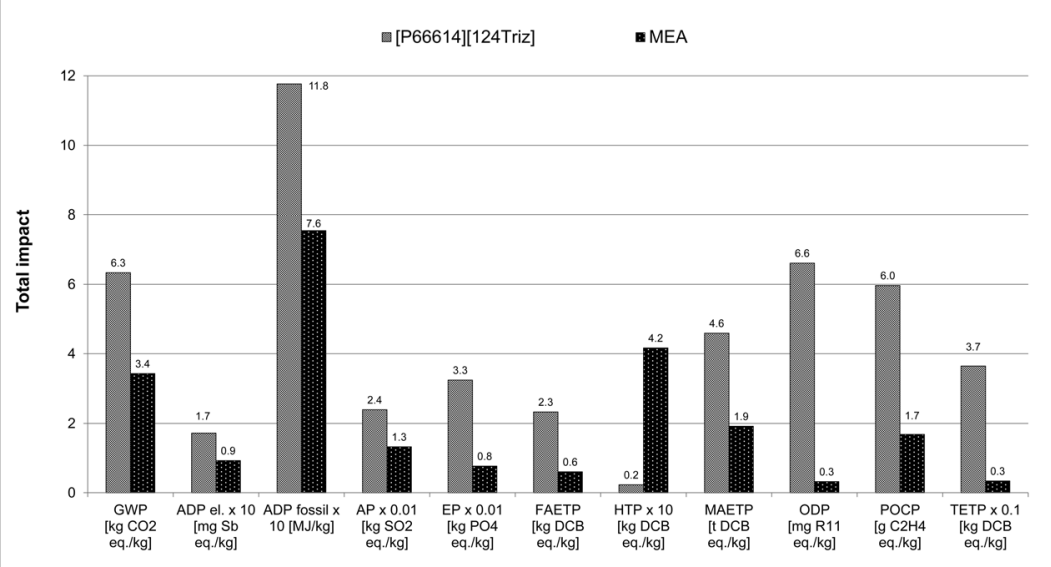

Fig. 7 Comparison of environmental impacts of $\left[\mathrm{P}_{66614}\right][124$ Triz] and MEA per kg of substance (data for MEA production sourced from Ecoinvent. The values for some impacts have been scaled to fit on the scale. The original values can be obtained by multiplying the value shown on the $y$-axis by the scaling factor given on the $x$-axis. For impacts nomenclature, see Fig. 5).

with the highest single contribution from phosphine at 30\%). The contribution of energy is relatively small (6.7\% on average) and that of transport and waste treatment negligible.

Therefore, these results suggest that the main opportunities for improvements lie in reducing the impacts associated with the raw materials, either through their substitution or improvements in their respective production processes. Furthermore, energy integration and use of low-carbon options would help to reduce GHG emissions from the production of $\left[\mathrm{P}_{66614}\right][124 \mathrm{Triz}]$.

3.3.4.2 Comparison of impacts with MEA. To find out if $\left[\mathrm{P}_{66614}\right][124 \mathrm{Triz}]$ is an environmentally sustainable alternative to MEA, commercially the most-widely used sorbent for $\mathrm{CO}_{2}$ capture, their impacts are compared in Fig. 7. The results suggest that $\left[\mathrm{P}_{66614}\right][124 \mathrm{Triz}]$ has higher environmental impacts than MEA for 10 out of the 11 categories, ranging from 55\% higher ADP fossil to 20 times higher ODP, with GWP nearly twice as high. The reason for a particularly high ODP is the trichloromethane used in preparation of the anionic resin, which contributes $90 \%$ to the total impact. As indicated in Fig. 7, the only impact for which MEA is an environmentally worse option than $\left[\mathrm{P}_{66614}\right][124 \mathrm{Triz}]$ is HTP, which is 18 times higher for MEA - this is due to its high toxicity. ${ }^{28}$

Therefore, these results suggest that $\left[\mathrm{P}_{66614}\right][124 \mathrm{Triz}]$ is environmentally less sustainable than MEA and would not be a viable replacement alternative. However, given the goal of the study, this comparison has been carried out per kg of each substance produced, which may be misleading. Instead, they should be compared on the basis of their performance in $\mathrm{CO}_{2}$ capture process. Since these data are not available for either of the substances, we consider their respective sorption capacities as the best proxy parameter available at present. The sorption capacity of $\left[\mathrm{P}_{66614}\right][124 \mathrm{Triz}]$ is reportedly equal to $1.01 \mathrm{~mol} \mathrm{IL}$ per mol $\mathrm{CO}_{2} \cdot{ }^{7}$ For MEA, both the theoretical (estimated) and actual (pilot plant) absorption capacities are considered, equal to 2 (ref. 29) and 2.44 mol MEA per mol $\mathrm{CO}_{2},{ }^{30}$ 


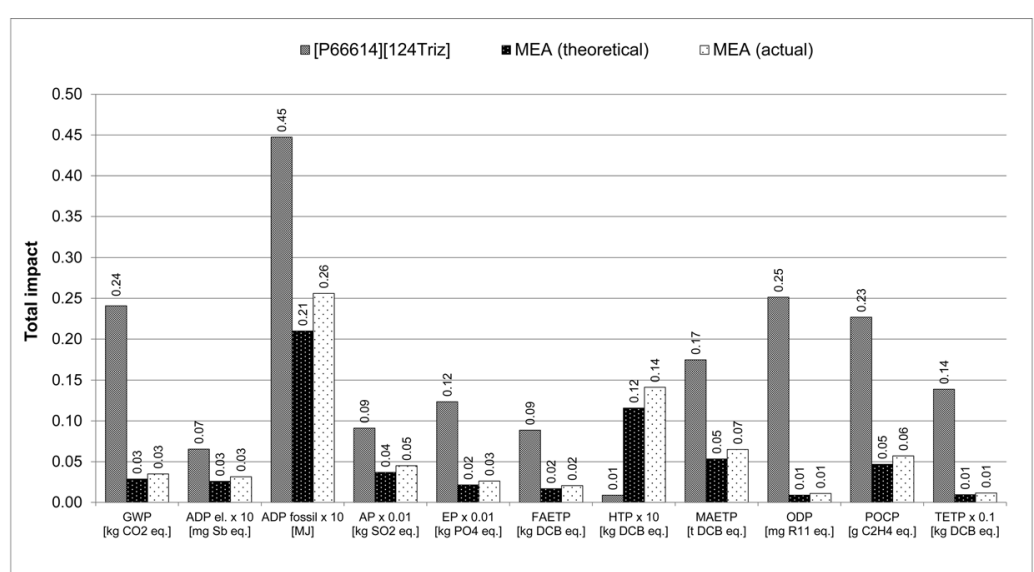

Fig. 8 Comparison of environmental impacts of $\left[\mathrm{P}_{66614}\right][124 \mathrm{Triz}]$ and MEA per kg of $\mathrm{CO}_{2}$ captured [The rate of reuse of $99.997 \%$ assumed for both $\left[P_{66614}\right][124 T r i z]$ and MEA. Data for $\mathrm{CO}_{2}$ absorption capacities sourced from literature: $\left[\mathrm{P}_{66614}\right][124 \text { Triz] }]^{7}$ and MEA. ${ }^{7,29,30}$ For MEA, "theoretical" represents an estimated (Xie et al. 2010) and "actual" an average sorption capacity achieved in a pilot plant (Sønderby et al. 2013). The values for some impacts have been scaled to fit on the scale. The original values can be obtained by multiplying the value shown on the $y$-axis by the scaling factor given on the $x$-axis. For impacts nomenclature, see Fig. 5].

respectively. Therefore, on a mole-ratio basis, $\left[\mathrm{P}_{66614}\right][124$ Triz $]$ captures more $\mathrm{CO}_{2}$ than MEA. It has also been assumed that both sorbents are reused at a rate of $99.997 \%$, based on the reported reuse of MEA. ${ }^{6,31}$

As shown in Fig. 8, the environmental impacts of the IL are now significantly higher than those of MEA, ranging from two times higher ADP fossil to 23-28 higher ODP for both the theoretical and actual MEA absorption capacities; global warming potential is eight times greater. The exception to this is HTP, which is on average 13 times higher for MEA. This is due to much more IL being required than MEA to capture the same amount of $\mathrm{CO}_{2}(557.5 \mathrm{~g} v s .122 \mathrm{~g}$ or $149 \mathrm{~g}$ of MEA per kg of $\mathrm{CO}_{2}$ ). However, these results should be interpreted with care as they are based purely on the sorption capacities and, owing to a lack of data, they do not take into account other aspects, such as process operating conditions, regeneration and degradation of the sorbents, etc. Furthermore, given the lack of real industrial data, many assumptions had to be made to estimate the impacts of the IL, which could lead to uncertainties. Therefore, to test the robustness of the results, sensitivity and uncertainty analyses have been carried out as discussed next.

\subsubsection{Sensitivity and uncertainty analyses}

Sensitivity analysis. The LCA findings presented in Section 3.3.4.1 suggest that the raw materials are the main hotspots in the production of $\left[\mathrm{P}_{66614}\right][124 \mathrm{Triz}]$ across all the impacts. Energy is also a hotspot for GWP and ADP fossil. Thus, the assumptions for these two life cycle stages have been examined through the sensitivity analysis to understand how they may affect the impacts. For the raw materials for which proxy data were used (1-hexene, 1-tetradecanol, formamide and hydrazine hydrate), the effect of using these data has been considered by varying the impacts of these materials (arbitrarily) by $\pm 50 \%$. For energy, the 


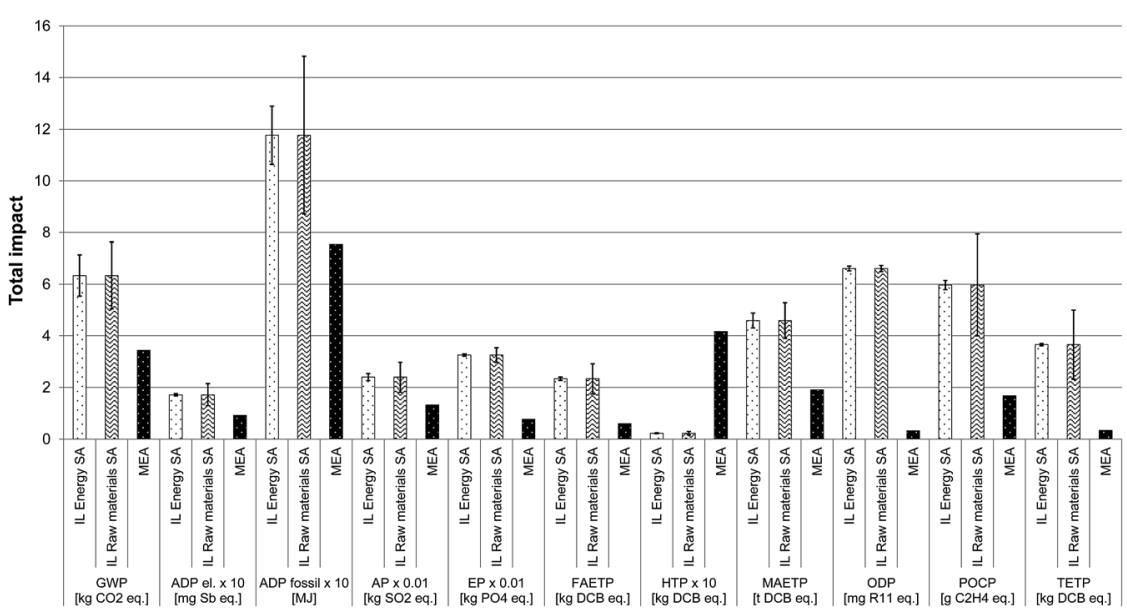

Fig. 9 Sensitivity analysis for the assumptions on the raw materials and energy used in the production of [ $\left.\mathrm{P}_{66614}\right][124 \mathrm{Triz}]$ and comparison of impacts with MEA (all impacts expressed per kg of substance. IL energy SA: ionic liquid energy sensitivity analysis. IL raw materials SA: ionic liquid raw materials sensitivity analysis. The values for some impacts have been scaled to fit on the scale. The original values can be obtained by multiplying the value shown on the $y$-axis by the scaling factor given on the $x$-axis. For impacts nomenclature, see Fig. 5).

validity of the theoretical estimates has also been tested by changing the consumption by $\pm 50 \%$.

Fig. 9 shows that the results are much more sensitive to the assumptions for the raw materials than for energy; this is to be expected since the former are the

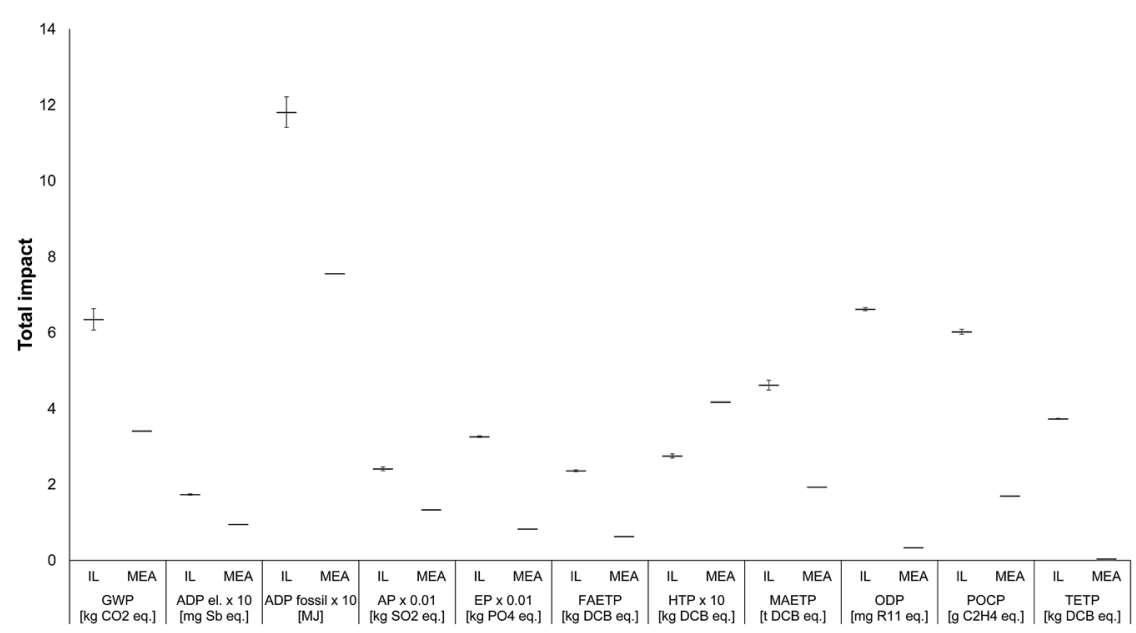

Fig. 10 Uncertainty analysis related to the estimates of energy used in the production of [P $\left.{ }_{66614}\right][124 T r i z]$ and comparison of impacts with MEA [all impacts expressed per $\mathrm{kg}$ of substance. For the IL, the horizontal bars represent the expected (mean) values and the error bars the range between the $10^{\text {th }}$ and $90^{\text {th }}$ percentile. The values for some impacts have been scaled to fit on the scale. The original values can be obtained by multiplying the value shown on the $y$-axis by the scaling factor given on the $x$-axis. For impacts nomenclature, see Fig. 5]. 
main hotspot. However, in both cases, the lowest values for the impacts of the IL are still significantly higher than for MEA. For example, if energy consumption is $50 \%$ lower than estimated, GWP is still $80 \%$ higher than for MEA. If the impacts of the above-mentioned four raw materials are $50 \%$ smaller than assumed originally, GWP is $50 \%$ higher than for MEA. Therefore, these findings suggest that the estimates for energy consumption and the assumptions for the missing raw materials data are robust.

Uncertainty analysis. To test the level of confidence in the results, a Monte Carlo simulation with 10000 iterations has been performed, generating the probabilistic results for the impacts. The simulation has been carried out using GaBi which enables the uncertainty to be estimated with respect to the quantities of materials and energy used in the system. As the quantities of the raw materials are quite robust, the focus of the uncertainty analysis has been on energy consumption, since these values were estimated rather than measured. Both the consumption of heat and electricity have been varied, again assuming an arbitrary range of $\pm 50 \%$.

The results of the Monte Carlo simulation are given in Fig. 10, with the horizontal lines representing the mean (expected) values and the error bars the spread of results between the $10^{\text {th }}$ and $90^{\text {th }}$ percentiles, indicating that we can expect impacts to fall between this range with a $90 \%$ confidence level. As can be seen, there is little variation in the impacts, with all categories still being much higher for the IL than MEA (except for HTP, as before). These results suggest a high confidence in the original findings that $\left[\mathrm{P}_{66614}\right][124 \mathrm{Triz}]$ has significantly higher impacts than MEA. Therefore, in the next and final step of the methodology, recommendations can be made on how its impacts could be reduced.

\subsection{Step 4: Recommendations}

As discussed in Section 3.3.4.1, the main hotspot in the life cycle of $\left[\mathrm{P}_{66614}\right]$ [124Triz] is the production of $\left[\mathrm{P}_{66614}\right] \mathrm{Cl}$, which is a precursor for $\left[\mathrm{P}_{66614}\right][\mathrm{OH}]$, which in turn is one of the main raw materials used in the synthesis of $\left[\mathrm{P}_{66614}\right]$ [124Triz] (see Fig. 3). The synthesis route for $\left[\mathrm{P}_{66614}\right] \mathrm{Cl}$ considered in this study is based on Cytec's synthesis route for phosphonium-based ionic liquids, which uses trihexylphosphine as the main reactant. Trihexylphosphine is commonly synthesised from phosphine gas, which is highly toxic to humans when inhaled. For example, acute exposure to phosphine can cause respiratory and cardiovascular damage and liver or renal failure, which in some cases can lead to death. ${ }^{32}$ Furthermore, phosphine gas has a significantly higher GWP $\left(15.8 \mathrm{~kg} \mathrm{CO}_{2}\right.$ eq. per $\mathrm{kg}$ ) than the average inorganic chemical compound (1.86 $\mathrm{kg} \mathrm{CO}_{2}$ eq. per $\mathrm{kg}$ ) owing to the use of white phosphorus.

Alternatively, it is possible to synthesise $\left[\mathrm{P}_{66614}\right] \mathrm{Cl}$ from aluminium trialkyl and phosphorus trichloride, as suggested by Hall et al. ${ }^{33}$ and Umeno and Takita. ${ }^{34}$ The proposed synthesis route consists of a phosphine-free multi-step process for preparing quaternary phosphonium salts. However, a full LCA study should be conducted to evaluate the potential environmental advantages of producing $\left[\mathrm{P}_{66614}\right] \mathrm{Cl}$ via this alternative route. Furthermore, a significant reduction in ODP could be achieved by substituting trichloromethane, used for preparation of the anionic resin, with another non-ozone depleting substance. However, care should be taken in choosing the substance to avoid increasing other impacts, such as GWP or HTP. 


\section{Conclusions}

This paper has proposed a novel methodology for estimating life cycle environmental impacts of ILs under development, with the aim of identifying hotspots and aiding synthesis and selection of more sustainable sorbents for $\mathrm{CO}_{2}$ capture. The example of $\left[\mathrm{P}_{66614}\right][124 \mathrm{Triz}]$ was used to illustrate the application of the methodology by estimating the impacts of its production from cradle to gate and comparing it to MEA, currently the most-widely used sorbent for $\mathrm{CO}_{2}$ capture. The case study also shows how to deal with real-life situations in the early development stages of chemicals when scant data are available.

The results suggest that 10 out of 11 environmental impacts considered are higher for $\left[\mathrm{P}_{66614}\right][124 \mathrm{Triz}]$ than for MEA. This includes GWP, which is estimated at $6.3 \mathrm{~kg} \mathrm{CO} \mathrm{CO}_{2}$ eq. per $\mathrm{kg}$ of $\left[\mathrm{P}_{66614}\right][124 \mathrm{Triz}]$, compared to $3.4 \mathrm{~kg} \mathrm{CO} \mathrm{CO}_{2}$ eq. per $\mathrm{kg}$ of MEA. The only exception is human toxicity potential which is 18 times higher for MEA than for $\left[\mathrm{P}_{66614}\right][124 \mathrm{Triz}]$. When the sorption capacities of the two substances are taken into account, the difference in the impacts is even higher in favour of MEA. This is largely due to the many precursors and energy used in the synthesis of the IL.

Nevertheless, owing to a lack of data, it is not possible to determine at this stage whether the use of this (or any other) IL would lead to a more sustainable $\mathrm{CO}_{2}$ capturing process overall, when operating conditions are taken into account, including sorbent regeneration, reuse and degradation. For that reason, further research will be required to examine fully the environmental sustainability of using ILs as $\mathrm{CO}_{2}$ sorbents. However, one of the main limitations is that, unlike other established processes, the industrial production of ILs cannot be simulated using simulation software such as Aspen Plus, because ILs are not supported in the existing component databanks. This is a similar problem to that experienced with LCA databases which will need to be addressed in the near future to ensure more sustainable production of ILs.

It should also be noted that, although the focus here has been on ILs, the proposed methodology is applicable to other chemicals. Further research is recommended to demonstrate how it can be used to help improve the environmental sustainability of other chemicals at an early design stage.

\section{Acknowledgements}

This work was carried out as part of the "4CU" Programme Grant, aimed at sustainable conversion of carbon dioxide into fuels, led by The University of Sheffield and carried out in collaboration with The University of Manchester, Queen's University Belfast and University College London. The authors acknowledge gratefully the UK Engineering and Physical Sciences Research Council (EPSRC) for supporting this work financially (Grant No. EP/K001329/1).

\section{References}

1 J. D. Figueroa, T. Fout, S. Plasynski, H. McIlvried and R. D. Srivastava, Advances in $\mathrm{CO}_{2}$ capture technology-The U.S. Department of Energy's Carbon Sequestration Program, Int. J. Greenhouse Gas Control, 2008, 2(1), 9-20. 
2 EASAC, Carbon capture and storage in Europe, European Academies Science Advisory Council, ISBN: 978-3-8047-3180-6. Available in: http:/www.easac.eu/ fileadmin/Reports/Easac_13_CCS_Web_Complete.pdf, 2013.

3 P. Styring, D. Jansen, H. de Coninck, H. Reith and K. Armstrong, Carbon Capture and Utilisation in the Green Economy. Centre for Low Carbon Futures, Available at: http://co2chem.co.uk/wp-content/uploads/2012/06/CCU\%20in\% 20the\%20green\%20economy\%20report.pdf, 2011.

4 R. Notz, H. P. Mangalapally and H. Hasse, Post combustion $\mathrm{CO}_{2}$ capture by reactive absorption: Pilot plant description and results of systematic studies with MEA, Int. J. Greenhouse Gas Control, 2012, 6, 84-112.

5 E. S. Rubin, H. Mantripragada, A. Marks, P. Versteeg and J. Kitchin, The outlook for improved carbon capture technology, Prog. Energy Combust. Sci., 2012, 38(5), 630-671.

6 L. Zhu, G. W. Schade and C. J. Nielsen, Real-Time Monitoring of Emissions from Monoethanolamine-Based Industrial Scale Carbon Capture Facilities, Environ. Sci. Technol., 2013, 47(24), 14306-14314.

7 S. F. R. Taylor, C. McCrellis, C. McStay, J. Jacquemin, C. Hardacre, M. Mercy, et al., $\mathrm{CO}_{2}$ Capture in Wet and Dry Superbase Ionic Liquids, J. Solution Chem., 2015, 1-17.

8 X. Zhang, X. Zhang, H. Dong, Z. Zhao, S. Zhang and Y. Huang, Carbon capture with ionic liquids: overview and progress, Energy Environ. Sci., 2012, 5(5), 66686681.

9 J. F. Brennecke and B. E. Gurkan, Ionic Liquids for $\mathrm{CO}_{2}$ Capture and Emission Reduction, J. Phys. Chem. Lett., 2010, 1(24), 3459-3464.

10 B.-S. Lee and S.-T. Lin, Screening of ionic liquids for $\mathrm{CO}_{2}$ capture using the COSMO-SAC model, Chem. Eng. Sci., 2015, 121, 157-168.

11 R. G. Reddy, Novel applications of ionic liquids in materials processing, J. Phys.: Conf. Ser., 2009, 165(1), 012076.

12 ISO, ISO 14040-Environmental Management - Life Cycle Assessment Principles and Framework. Available at: http://www.iso.org/iso/ catalogue_detail?csnumber $=37456 ; 2006$.

13 ISO. ISO 14044-Environmental Management - Life Cycle Assessment Requirements and Guidelines. Available at:http://www.iso.org/iso/ catalogue_detail?csnumber=38498, 2006.

14 N. Hollingsworth, S. F. R. Taylor, M. T. Galante, J. Jacquemin, C. Longo, K. B. Holt, et al., Reduction of Carbon Dioxide to Formate at Low Overpotential Using a Superbase Ionic Liquid, Angew. Chem., Int. Ed., 2015, 54(47), 14164-14168.

15 C. J. Bradaric, A. Downard, C. Kennedy, A. J. Robertson and Y. Zhou, Industrial preparation of phosphonium ionic liquids, Green Chem., 2003, 5(2), 143-152.

16 M. M. Rauhut, H. A. Currier, A. M. Semsel and V. P. Wystrach, The Free Radical Addition of Phosphines to Unsaturated Compounds, J. Org. Chem., 1961, 26(12), 5138-5145.

17 H. Demail, J. C. Schweickert and P. Le Gars, Process for the preparation of alkyl chlorides, US Pat. US 5723704 A. Available at: http:/www.google.co.uk/patents/ US5723704. 1998.

18 H. E. Petree, J. R. Pociask and G. Jt. Method for direct preparation for 1,2,4triazole from hydrazine and formamide, US Pat. US 4267347 A. Available at: http://www.google.co.uk/patents/US4267347, 1981. 
19 Thinkstep, Gabi V6.4. Thinkstep, https://www.thinkstep.com/software/gabi-lca/, 2014.

20 J. B. Guinée, M. Gorrée, R. Heijungs, G. Huppes, R. Kleijn and A. de Koning, Life cycle assessment: an operational guide to the ISO standards, Available at: http://media.leidenuniv.nl/legacy/new-dutch-lca-guide-part-1.pdf. 2001.

21 R. M. Felder and R. W. Rousseau, Elementary Principles of Chemical Processes, ed. N. J. Hoboken, John Wiley \& Sons, 2005.

22 A. Mehrkesh and A. T. Karunanithi, Energetic Ionic Materials: How Green Are They? A Comparative Life Cycle Assessment Study, ACS Sustainable Chem. Eng., 2013, 1(4), 448-455.

23 Ecoinvent, Ecoinvent database 2.1., Ecoinvent Centre, http:// www.ecoinvent.org/home.html, 2013.

24 NCBI. 1-Hexene, National Center for Biotechnology Information. Available at: https://pubchem.ncbi.nlm.nih.gov/compound/1-hexene\#section=Top, 2016.

25 H. Hasturk, E. Goguet-Surmenian, A. Blackwood, C. Andry and A. Kantarci, 1Tetradecanol Complex: Therapeutic Actions in Experimental Periodontitis, $J$. Periodontol., 2009, 80(7), 1103-1113.

26 R. W. Gora, S. J. Grabowski and J. Leszczynski, Dimers of Formic Acid, Acetic Acid, Formamide and Pyrrole-2-carboxylic Acid: an Ab Initio Study, J. Phys. Chem. A, 2005, 109(29), 6397-6405.

27 W. A. Rickelton, Phosphine and Its Derivatives, Kirk-Othmer Encyclopedia of Chemical Technology, John Wiley \& Sons, Inc., 2000.

28 DOW, Material safety data sheet for Monoethanolamine, The DOW Chemical Company, Available at: http://msdssearch.dow.com/ PublishedLiteratureDOWCOM/dh_0044/0901b80380044789.pdf?filepath= amines/pdfs/noreg/111-01388.pdf\&fromPage=GetDoc, 2003.

29 H.-B. Xie, Y. Zhou, Y. Zhang and J. K. Johnson, Reaction Mechanism of Monoethanolamine with $\mathrm{CO}_{2}$ in Aqueous Solution from Molecular Modeling, J. Phys. Chem. A, 2010, 114(43), 11844-11852.

30 T. L. Sønderby, K. B. Carlsen, P. L. Fosbøl, L. G. Kiørboe and N. von Solms, A new pilot absorber for $\mathrm{CO}_{2}$ capture from flue gases: Measuring and modelling capture with MEA solution, Int. J. Greenhouse Gas Control, 2013, 12, 181-192.

31 M. R. M. Abu-Zahra, L. H. J. Schneiders, J. P. M. Niederer, P. H. M. Feron and G. F. Versteeg, $\mathrm{CO}_{2}$ capture from power plants: Part I. A parametric study of the technical performance based on monoethanolamine, Int. J. Greenhouse Gas Control, 2007, 1(1), 37-46.

32 L. Assem and M. Takamiya, Phosphine: Toxicological overview, Health Protection Agency and Institute of Environment and Health, Cranfield Univeristy, Available at: https://www.gov.uk/government/uploads/system/uploads/attachment_data/ file/338253/HPA_Phosphine_toxicological_overview_v1.pdf, 2007.

33 R. E. Hall, A. Kessler and A. R. Mclain, Process for the preparation of phosphonium salts and phosphine oxides starting with aluminum trialkyl, US Pat. US 3459808 A. Available at: http://www.google.co.uk/patents/ US3459808, 1969.

$34 \mathrm{M}$. Umeno and S. Takita, Preparation process of quaternary phosphonium hydroxide, US Pat. US 4761493 A, Available at: http:/www.google.ch/patents/ US4761493, 1988. 